\title{
Pyrrolnitrin Biosynthesis From Rhizospheric Serratia Spp. With Antifungal Activity and Binding Interactions of PrnF With Ligands
}

\section{Shraddha P. Pawar}

Kavayitri Bahinabai Chaudhari North Maharashtra University Jalgaon

Ambalal B. Chaudhari ( $\sim$ ambchasls@gmail.com)

Kavayitri Bahinabai Chaudhari North Maharashtra University

\section{Research}

Keywords: Pyrrolnitrin, Serratia spp., NADPH dependent FMN-reductase, Modelling, Ramachandran plot

Posted Date: September 4th, 2020

DOI: https://doi.org/10.21203/rs.3.rs-56362/v1

License: @ (i) This work is licensed under a Creative Commons Attribution 4.0 International License. Read Full License 


\section{Abstract}

Pyrrolnitrin (PRN) from rhizobacteria displays a key role in biocontrol of phytopathogenic fungi in rhizospheric soil. Therefore, different rhizospheric soils were investigated for the prevalence of PRN producer in minimal salt (MS) medium containing tryptophan $(0.2 \mathrm{M} \mathrm{NaCl}$; pH 8$)$ using three successive enrichments. Of $12 \%$ isolates, only five bacterial strains had shown PRN secretion, screened with Thin Layer Chromatography $\left(R_{f} 0.8\right)$ and antifungal activity ( 27 mm) against phytopathogen. The phenetic and 16S rRNA sequence revealed the close affiliation of isolates (KMB, M-2, M-11, TW3, and TO2) to Stenotrophomonas rhizophila (KY800458), Enterobacter spp. (KY800455), Brevibacillus parabrevis (KY800454), Serratia marcescens (KY800456) and Serratia nemtodiphila (KY800457). Purified compound from isolates was characterised using UV, IR, HPLC, LCMS and GCMS as PRN. However, BLASTn hit of prn gene sequences from both Serratia species showed 99\% similarity with NADPH dependent FMN reductase component (prnF). The homology protein model of prnF was developed from translated sequence of $S$. marcescens TW3 with chromate reductase of Escherichia coli K-12. Docking with FMN and NADPH was performed. The study demonstrated the possible role of prnF NADPH dependent FMN reductases in prnD for supply of reduced flavin in rhizobacterial strain of Serratia spp. which may pave a way to understand PRN production.

\section{Introduction}

Pyrrolnitrin [3-chloro-4-(3'-chloro-2'-nitrophenyl) pyrrole; PRN], is a organo-halo-phenylyrrole metabolite mostly produced by narrow range of rhizospheric Gram negative bacteria (Schmidt et al. 2009) that has broad spectrum antimicrobial activities including, antifungal activity against a wide range of Deuteromycetes, Ascomycetes, Basidiomycetes (Arima et al. 1964; Chernin et al. 1996; Kirner et al. 1998; Schmidt et al. 2009; Pawar and Chaudhari 2019) and nematicidal activity (Nandi et al. 2015). PRN has been documented for (i) insulin secretion by INS-1 cells, but cytotoxic to pancreatic $\beta$-cells at low and high concentration, respectively (Hong et al. 2014), (ii) inhibitory activity $\left(8 \mu \mathrm{gml}^{-1}\right.$ ) against Mycobacterium tuberculosis and M. avium (Roberto et al. 1998), (iii) potential importance in the suppressive of soil to phytopathogens for study of plant species richness and (iv) key role in induced systemic resistance in plants (Ellen et al. 2012; Hong et al. 2014; Weisser et al. 2017). Now, PRN has been used as a lead structure in the development of stable phenylpyrrole derivatives (fludioxonil and fenpiclonil) as an alternative fungicide to chemical pesticides in agriculture (Ligon et al. 2000; Keum et al. 2009; Bhardwaj et al. 2015). Currently, chlorinated phenylpyrroles has received more attention in agricultural and pharmaceutical as the most effective allelochemicals (van Pee 2012; Frese and Sewald 2014) for biocontrol against various pathogens (Arima et al. 1964; Bhardwaj et al. 2015; Pawar et al. 2019) on the basis of (i) inhibitory activities towards NADH and succinate supported terminal electron transport in mitochondria, (ii) destructive influence to the cellular membrane integrity by combination with phospholipids causing inhibition of cellular respiration in fungi (Nose and Arima 1969; Tripathi and Gottlieb 1969; El-Banna and Winkelmann 1998),(iii) uncoupling of oxidative phosphorylation at low concentration, and (iv) cessation of cell growth due to accumulation of glycerol, stimulation of triacetyl glycerol leading to leakage of cell membrane (Jespers et al. 1995).

Hence, PRN has been recommended for (i) treatment of Tinea pedis and dermatophytic infections as an antimycotic topical medicine under the trade name PYRO-ACE in Japan (Gorman and Lively 1967), (ii) control of post-harvest diseases of apple, pear and cut flower caused by Botrytis cinerea (Tawara et al. 1989; Hammer et al. 1993) and soil borne phytopathogens in a variety of plants (Sako et al. 2002).

Presently, PRN is biosynthesised by rhizobacterial strains of Burkholderia cepacia, B. pseudomallei, Corallococcus exigus, Cystobacter ferrugineus, Enterobacter agglomerans, Myxococcus fulvus, Serratia spp., fluorescents and non-fluorescent Pseudomonas spp. (Gerth et al. 1982; Roitman et al. 1990; Chernin et al. 1996; Roberts et al. 2007; Costa et al. 2009) and reported for the presence of prn operon (Hamill et al. 1967; Gerth et al. 1982; Roitman et al. 1990; Chernin et al. 1996; El-Banna and Winkelmann 1998; Roberts et al. 2007; Costa et al. 2009; Parry et al. 2011). The gene cluster (prnA through prnD) for PRN was reported in Bulkholderia cepacia, Pseudomonas pyrrocinia and Serratia spp. (Hammer et al. 1997) and newly discovered prnF (flavin reductase) in close proximity to prnD constituted part of the gene cluster (Lee and Zhao 2007) for PRN biosynthesis from tryptophan through chlorination, followed by rearrangement, regioselective chlorination, oxidation of amino group in the presence of reduced flavin by flavin reductase (Hammer et al. 1997; van Pee 2001). Among these, prn gene sequences revealed more conservation between Burkholderia, Pseudomonas, Serratia derived sequences and hence, prnD gene constitute specific detection system and de Souza (2003) developed specific primers located in the prnD gene to assess phylogenetic relationship in PRN producing rhizobacteria. prnD (aminopyrrolnitrin oxygenases) in the pathway catalyse a 6-electron oxidation of amine group of aminopyrrolnitrin to a nitro group to form PRN in the presence of reduced flavin (Nakatsu et al. 1995). The evidences of prnF and prnD to form a two component NADPH dependent monooxygenase was recently delineated from prnD-catalyzed arylamine oxidation in Pseudomonas fluoresces Pf-5 (Hohaus et al. 1997; Tiwari et al. 2012).

Besides, PrnF was also demonstrated to stimulate (i) chorinaton by PrnA and PrnC activity in PRN synthesis (Richard 2003), (ii) halogenation of aromatic compounds by RebH and ThdH in rebecamycin, thienodolin (Sanchez et al. 2002; Sebold et al. 2006) and (iii) bromination by BrvH in marine metagenomes (Neubauer et al. 2018) and reported to catalyse the reduction of flavin such as flavin mononucleotide, flavin adenine dinucleotide and riboflavin by $N A D(P) H$ to form reduced flavin which is required to activate oxygen by the terminal oxygenase (Hammer et al. 1997). At present, prnF was identified via sequence analysis only from Pseudomonas fluorescence Pf-5 and characterized to supply reduced flavin to prnD oxygenase component to function in PRN synthesis (Hammer et al. 1997). On this premise, we initiated our study with (i) isolation and selection of rhizospheric bacteria from eco-habitats for extracellular secretion of PRN, (ii) identification of rhizobacterial strains with phenetic and 16S rRNA gene sequencing, (iii) investigation of prnD gene in PRN secretion from both Serratia spp with prnD specific primers (Souza and Raaijmakers 2003) (iv) characterization of prnF component encoding flavin reductase based on bioinformatic studies, and ( $v$ ) analysis of structural model of prnF protein from both Serratia strains and compared it with PrnF protein models of reference strain in order to find out structural similarity. Finally, PRN was extracted from five selected rhizobacterial isolates and characterized for (a) chemical identity with analytical tools, and (b) bioactivity against reference phytopathogen.

\section{Materials And Methods}

\section{Growth media, chemicals, phyto-pathogens}


Various media viz. King's B (KB), Trypan Blue Tetracycline (TBT) and Mineral salt (MS) medium (pH 8.0) were used for isolation of bacteria and screening for secretion of PRN. Plant pathogen Fusarium oxysporum MTCC 9913 was grown and maintained on Potato Dextrose Agar (PDA) for antimicrobial assay and stored at $4{ }^{\circ} \mathrm{C}$. All chemicals as well as solvents used were of reagent grade and procured from M/s S.D. Fine Chemicals, Mumbai and culture media were purchased from Hi-Media Pvt. Ltd., Mumbai.

\section{Soil analysis and isolation, enrichment of bacteria for halo-metabolite secretion}

The rhizospheric soil was taken from radish (RJ) grown in nearby area $\left(21.0076578{ }^{\circ} \mathrm{N} 75.5626039^{\circ} \mathrm{E}\right)$ and rice cultivated in saline (RD) of coastal area $\left(19.9810649^{\circ} \mathrm{N} 72.7451817^{\circ} \mathrm{E}\right.$ ) (Table 1). The crop plants were uprooted from each site and soil surrounding the root surface of plants from each location was taken to the laboratory and stored at $4{ }^{\circ} \mathrm{C}$. Analysis of physico-chemical parameters of soil samples was carried out as per standard protocols at Jain Irrigation System Ltd. (JISL), Jalgaon (Gupta 1999; Jones 2001; Tondon 2005).

Table 1

Physico-chemical and particle size characterization of soil samples collected from rhizospheric area of different habitats us€

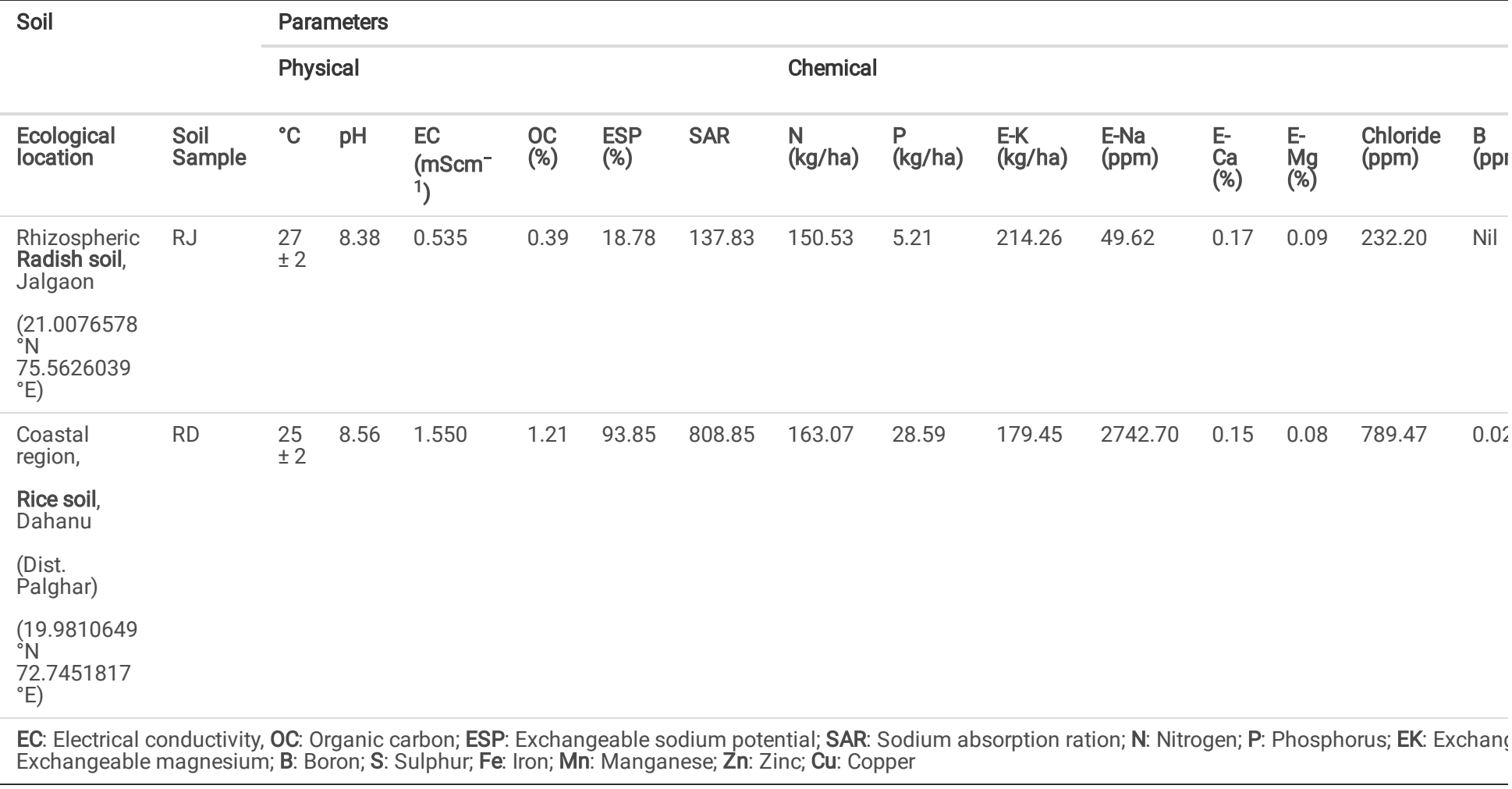

For isolation of halometabolite secreting bacteria, rhizosphere soil adhering to the roots of rice plant and root exudates of radish plant were collected in sterile container. Each sample (10 g soil with roots) was placed in $500 \mathrm{ml}$ Erlenmeyer flasks with active volume of $100 \mathrm{ml}$ containing sterile growth medium KB, TBT (Hagedorn et al. 1987) and MS medium (de Souza and Raaijmakers 2003) amended with 1.5\% NaCl; was incubated for $48 \mathrm{~h}$ at room temperature on a rotary shaker (120 rpm). After three successive enrichments on the same medium, aliquots of decimal dilution $\left(10^{-6}\right)$ were spread on respective agar medium; typical morphotype colonies were selected and maintained on nutrient agar slant at $4{ }^{\circ} \mathrm{C}$ before screening for extracellular PRN secretion.

\section{Screening of bacteria for PRN production}

Each pre-grown bacterial isolate (OD 0.5 at $A_{600}$ ) was inoculated in $50 \mathrm{ml}$ of MS medium amended with $0.06 \%$ D-tryptophan kept at $28{ }^{\circ} \mathrm{C}$ on rotary shaker (120 rpm) for initial $24 \mathrm{~h}$ followed by $96 \mathrm{~h}$ of dark and static condition as per deSouza and Raaijmakers (2003). The culture broth was centrifuged (R-24 REMl, Mumbai) at $4650 \times \mathrm{g}$ for $15 \mathrm{~min}$ to separate cell biomass. Cell free supernatant was acidified to $\mathrm{pH} 5.0$ by $5 \mathrm{~N} \mathrm{HCl}$ and subsequently, extracted in ethyl acetate (1:3) thrice. The organic phase was evaporated, residue dissolved in $1 \mathrm{ml}$ of methanol and stored at $-20^{\circ} \mathrm{C}$ for further characterization. Initially, each sample was analysed for characteristic (i) optical spectral pattern (190-800 nm), (ii) pyrrole ring using Ehrlich's reagent (Kessler et al. 1990) and (iii) chlorine moiety by IR.

\section{Chemical characterization}

Methanol extract from each sample $(50 \mu \mathrm{l})$ was applied onto Silica gel $60 \mathrm{~F}_{254}$ plates $(20 \times 20 \mathrm{~cm}$, Merck, Germany). Chromatography run was carried out with chloroform: acetone (9:1) as performed by Burkhed et. al (1994) and de Souza and Raaijmakers (2003) and (i) visualized under UV trans-illuminator (254 nm), (ii) subsequently treated with Ehrlich's reagent (2\% p-dimethylaminobenzaldehyde) in $95 \%$ ethanol: $\mathrm{HCl}$ as 1:1 for purple coloured spot. Relative distance of each coloured spot to solvent front was calculated as $R_{f}$ value for each sample.

The IR spectra of each extracted sample was recorded for the presence of functional group using Fourier transform infrared spectroscopy (FTIR) (88522 Spectrum Two TM, Perkin-Elmer, USA) in the range of $4000-350 \mathrm{~cm}^{-1}$ spectral region. Each sample was analysed using \% transmission with devoid of sample as control. 
High performance liquid chromatography (HPLC) (Younglin (S.K) Gradient System; Software: Autochro-3000) of each sample was conducted at Shree Analytics, Jalgaon (El-Banna and Winkelmann 1998). The HPLC column used was a C18 (4.6 mm x $250 \mathrm{~mm}$ (YMC; particle size packing 5 um). The sample was detected with isocratic system using acetonitrile: water (20 to 100\%) as solvent phase. Flow rate was $0.7 \mathrm{mlmin}^{-1}$ with ambient temperature and absorbance was checked at $220 \mathrm{~nm}$ (UV Detector-730D). Molecular mass spectrum was determined by LC coupled with mass spectrophotometer (LC-MS) (Waters Micromass Q-Tof Micro, USA) at Punjab University, Chandigarh. MS analysis was conducted to screen LC eluent for PRN.

Further, characterization of extracted sample from two bacterial isolates (TW-3 and TO-2) were also conducted by gas chromatography (GC) at NCML, Hyderabad using Thermo TR-5 Column (30 m length, 0.32 ID, $5 \%$ phenyl poly siloxane) with the following conditions: carrier gas: Helium; flow: 2 mlmin ${ }^{-1}$; inlet: $250^{\circ} \mathrm{C}$; oven: $150{ }^{\circ} \mathrm{C}$ for $5 \mathrm{~min}, 15^{\circ} \mathrm{Cmin}^{-1}$ up to $250^{\circ} \mathrm{C}$, hold $10 \mathrm{~min}$; detector: $200{ }^{\circ} \mathrm{C}$; sample volume: $3 \mu \mathrm{L}$ with no split ratio (Schmidt et al. 2009 ). The mass of peak was determined at RT of $10.6 \mathrm{~min}$.

\section{Antagonistic activity of halometabolites towards phytopathogen}

Each extracted sample was examined for in vitro antagonistic activity towards test phytopathogen Fusarium oxysporum MTCC 9913 using agar-well diffusion assay (Ahmad et al. 2008). About $20 \mu \mathrm{l}$ of each extracted sample was applied against $10^{4}$ fungal spores $\mathrm{ml}^{-1}$ into $20 \mathrm{ml}$ of PDA and incubated at $28{ }^{\circ} \mathrm{C}$ for $240 \mathrm{~h}$. The growth of phytopathogen in the absence of active compound was monitored and used as a control for the antagonist assay. The zone of inhibition around wells $(\mathrm{mm})$ was estimated after 8 days of incubation. Each experiment was repeated twice, and data was analysed for standard deviation.

\section{Taxonomic identification of bacterial strains}

Preliminary identity of five selected bacterial isolates designated as, TO-2, TW-3, KMB, M-11, M-2 were examined using (i) cultural, morphological and microscopic examination, (ii) molecular characterization at Macrogen, South Korea, (iii) two bacterial strains TW-3 and TO-2 studied for (a) biochemical identification by Vitek-2 system (version 7.01) at Salvus Bioresearch Solution, Vadodara (Gujarat) and also, (b) utilization of carbohydrates and sugars by inoculating a loopful of pre-grown culture (24 h) into the wells of KB009 HiCarbo kit (KB009A/KB009B1/ KB009C).

\section{S rRNA sequencing and phylogenetic relationship}

For $16 \mathrm{~S}$ rRNA, reaction was performed in $25 \mu \mathrm{l}$ volumes using $20 \mathrm{ng}$ of template DNA, containing 15 pmol of each primer, PCR was performed in a $30 \mu \mathrm{l}$ reaction mixture with EF-Taq (SolGent, Korea). The sequence primer 785F 5' (GGA TTA GAT ACC CTG GTA) 3', 907R 5' (CCG TCA ATT CMT TTR AGT TT) 3' while PCR primer 27F 5' (AGA GTT TGA TCM TGG CTC AG) 3', 1492R 5' (TAC GGY TAC CTT GTT ACG ACT T) 3' was used for amplification. The PCR amplified DNA fragments were gel-purified using QIAquick ${ }^{\text {TM }}$ Gel Extraction Kit (250) (Qiagen, Hilden, Germany) and sequenced by using ABI3730 XL DNA Analyser (Applied Biosystems, Renton, USA) at Macrogen Inc (Seoul, South Korea).

The nucleotide sequence data were assembled and analysed using Basic Local Alignment Search Tool (BLAST) at NCBI. The phylogenetic relationship was inferred by neighbour-joining method using MEGA 7.0 software (Felsenstein 1985; Saitou and Nei 1987; Zuckerkandl and Pauling; Kumar et al. 2016). The resulted gene sequences have been submitted to the NCBI gene database and five bacterial cultures were deposited to culture collection centre at MTCC, Chandigarh and NCIM, Pune.

prn gene sequencing

PCR based detection of PRN coding gene (prn gene) from bacterial isolates (as determined by analytical tools) was carried out by using 25 ng of DNA template. For this purpose, prnD primers (PRND1 GGGGCGGGCCGTGGTGATGGA and PRND2 YCCCGCSGCCTGYCTGGTCTG) and reaction (3 $\mu$ l diluted heat lysed cell suspension $+1 \times$ PCR buffer $+1.5 \mathrm{mM} \mathrm{MgCl}_{2}+200 \mu \mathrm{M}$ of each dNTPs +20 pmol of each primer $+2.0 \mathrm{U}$ AmpliTaq polymerase) conditions (initial denaturation for 2 min at $95^{\circ} \mathrm{C}$ followed by 30 cycles at $95^{\circ} \mathrm{C}$ for $1 \mathrm{~min}$; annealing at $68{ }^{\circ} \mathrm{C}$ for $1 \mathrm{~min}$; and final extension at $72{ }^{\circ} \mathrm{C}$ for $1 \mathrm{~min}$ ) for amplification were carried out as per deSouza and Raaijmakers (2003) using PCR machine (DNA Engine Tetrad 2 Peltier Thermal Cycler, BIO-RAD). The PCR program for prn consisted of an initial denaturation at $94^{\circ} \mathrm{C}$ for $5 \mathrm{~min}$, followed by 40 cycles at $94{ }^{\circ} \mathrm{C}$ for 30 secs, annealing at $68{ }^{\circ} \mathrm{C}$ for 30 secs, followed by an extension at $72^{\circ} \mathrm{C}$ for $2 \mathrm{~min}$. The PCR amplified product was resolved in buffer using AxyPrep DNA gel extraction kit. All PCR based reactions were conducted using Big Dye (R) Terminator v3.1 cycle sequencing kit (Applied Biosystems, USA). The gene sequences were identified using similarity search against the available database with BLASTx. The prn gene sequences from each bacterial strain were deposited in NCBI GenBank database.

\section{Molecular modelling of PrnF protein}

The 3D structure of PrnF was generated using MODELLER (Sali and Blundell 1993; Fiser and Do 2000). A BLAST search of Protein Data Bank (PDB) indicated the significant sequence identity (85.93\%) with PrnF and chromate reductase in Escherichia coli K-12 (tseq1) possessing the highest bit score among all of the search results. The crystal structure of the $3 S V L$ (resolution $2.2 \AA$ ) was used as a template. The target sequence was aligned with template structure and the health of the template structure was checked using protein health module. The final model was build using information from template structures and validated using (i) ProSA web server, (ii) SAVES v5.0 and (iii) PROCHECK.

Protein-ligand docking simulations were performed using AutoDock4 and AutoDock Vina tool (Trott and Arthur 2015) in PyRx (Dallakyan and Arthur 2015) for initial screening. Ligands were obtained from the ZINC database and structure was corrected for (i) geometric, (ii) optimized atom numbers and, (iii) conformational issues using the repair tools like ChemDraw, Avogadro, etc. For the standard docking procedure, ligands were docked by defining a grid box with spacing $1 \AA$, center of $X=80.8924, Y=62.494$ and $Z=8.631$ and size of $25 \times 25 \times 25(\AA)$ pointing in $x, y$ and $z$ directions around the protein active site. After preparing the coordinate files, FMN and NADPH were docked with binding domains in order to see the bound conformations, binding affinity and possible protein-ligand interactions. PyMOL (Molecular Graphics System, Version 2.3 Schrodinger, LLC) and BIOVIA/Discovery Studio 2019 used for the visualization and structure analysis then lowest energy structure was used for post-docking analysis. 


\section{Results}

\section{Isolation and screening of halometabolite producing bacteria from rhizospheric soil}

The rhizospheric soil samples namely, RJ and RD were analysed for physico-chemical characteristics. The analysis of both soil (RJ and RD) are revealed in Table 1. The soil type of both RJ and RD samples appeared to be Loam and Sandy loam with high alkalinity and salinity, respectively. The saline soil likely harbour halometabolites (e.g. PRN) secreting bacteria in rhizosphere (van Pee 2001). Besides, the abundance of tryptophan in the root exudates of radish was reported earlier (Kravchenko et al. 2004) (Table 2), possibly a precursor for PRN biosynthesis in rhizospheric region. Hence, both salinity and tryptophan were incorporated in the selection medium for isolation of halometabolite secreting rhizobacteria in the present study. The evidences about prevalence of PRN secreting rhizobacteria from rhizospheric soil of grasslands and arable soil was reported earlier with PCR based approach (Garbeva et al. 2004).

Table 2

The amount of tryptophan secreted by the different genera of plants in rhizospheric soil

\begin{tabular}{|c|c|c|c|c|}
\hline S. $\mathbf{N}$. & Name of the Plant & \multicolumn{2}{|c|}{ Amount of tryptophan } & Reference \\
\hline 1. & Pea Plant (Pisum sativum) & $\mu \mathrm{g}$ & 0.5 & Morris and Johnson (1987) \\
\hline 2. & Oat (Avena sativa) & \multirow[t]{3}{*}{$\mathrm{Mm}$} & 0.25 & Barazani and Friedman (1999) \\
\hline \multirow[t]{2}{*}{3.} & Pigeon pea (Cajanus cajan) + Rhizobiom spp. wild S2 & & $\nabla 1.2 \pm 0.09$ & \multirow[t]{2}{*}{ Pandya et al. (1999) } \\
\hline & Pigeon pea (Cajanus cajan) + Rhizobium spp. mutant S14 & & $0.13 \pm 0.08$ & \\
\hline \multirow[t]{4}{*}{4.} & Tomato cultivars (Karmello) & \multirow{4}{*}{$\mathrm{ng}^{-1}$} & $5.3 \pm 0.7$ & \multirow[t]{4}{*}{ Kravchenko et al. (2004) } \\
\hline & Tomato cultivars (Aromato) & & $2.8 \pm 0.4$ & \\
\hline & Radish cultivars (Saksa nova) & & $293 \pm 35$ & \\
\hline & Radish cultivars (Teplichnyi) & & $390 \pm 42$ & \\
\hline \multirow[t]{4}{*}{5.} & Tomato & \multirow[t]{4}{*}{ Seedlings $^{-1}$} & $7.39 \pm 0.83$ & \multirow[t]{4}{*}{ Kamilova et al. (2006) } \\
\hline & Cucumber & & $1.81 \pm 0.28$ & \\
\hline & Sweet Pepper & & $23.9 \pm 0.83$ & \\
\hline & Radish & & $293 \pm 35$ & \\
\hline 6. & Cucumber & Plant $^{-1}$ & $4.9 \pm 4.5$ & Liu et al. (2007) \\
\hline \multirow[t]{2}{*}{7.} & Soya bean FN 4.10 & \multirow[t]{2}{*}{ nmol plant ${ }^{-1}$} & 2.79 & \multirow[t]{2}{*}{ Yaryura et al. (2008) } \\
\hline & Soya bean FN 4.85 & & 0.29 & \\
\hline \multirow[t]{2}{*}{8.} & Corn & \multirow[t]{2}{*}{$\mathrm{Mmol} \mathrm{ml}^{-1}$} & $0.05-0.3$ & \multirow[t]{2}{*}{ Tahat et al. (2010) } \\
\hline & Tomato & & $0.1-0.2$ & \\
\hline \multirow[t]{2}{*}{9.} & \multirow[t]{2}{*}{ Rice (Oryza sativa) } & \multirow[t]{2}{*}{$\mathrm{nM} \mathrm{g}^{-1}$} & $1.026-1.345$ & \multirow[t]{2}{*}{ Tawaraya et al. (2013) } \\
\hline & & & $0.992-1.856$ & \\
\hline 10. & Clover (seedling) & $\mathrm{gL}^{-1}$ & $7.5 \times 10^{-6}$ & Kefford et al. (1960) \\
\hline
\end{tabular}

Total 111 bacterial strains (40 and 71 bacterial morphotypes) were isolated from rhizospheric soil (radish and rice). The preliminary analysis of methanolic extracts of cell free broth from all isolates for PRN was detected with (i) UV-Vis spectrum (Fig. 1a) and (ii) Ehrlich's test using Ehrlich's reagent. Among these, only 40 isolates showed characteristic Ehrlich's reagent spectra (Kessler et al. 1990) of pyrrole ring at 520-570 nm (Fig. 1b). Analogous to UV-Vis spectra of 40 samples, TLC plate developed violet coloured spot after Ehrlich's reagent reaction with $\mathrm{R}_{f}$ value of 0.8 (Fig. $2 \mathrm{a}$ ) which are consistent with the earlier reports (de Souza and Raaijmakers 2003; Parry et al. 2011).

The UV spectrum of the pyrrole compound yielded $\lambda_{\max } / \mathrm{nm}$ (relative absorbance) of 212 (3.425), 252 (1.88); 212 (3.425), 252 (1.882); 226 (4.0123), 252 (2.399); 211 (1.5982), 252 (1.88); 220 (2.7584), 252 (1.194); for bacterial isolates KMB, M-11, M-2 TW-3 and TO-2 respectively (Fig. 1a). PRN extracted from each bacterial strain KMB, M-11, M-2, TW-3 and TO-2 quantified according to Chernin et al. (1996) for the same molecular weight of 257.07 D at absorbance of $252 \mathrm{~nm}$ using $1 \mathrm{~cm}$ path length against sample devoid of PRN, (ethanol as blank) and calculated using extinction coefficient ( $\epsilon=7500)$ appears 64.43 , $82.26,64.51,64.43$ and $41.02{\mu \mathrm{gml}^{-1}}^{1}$, respectively. The PRN reported in this study was 8-16.5 times more than the earlier reports from E. agglomerans (1996) and B. cepacia (1998).

Further, FT-IR analysis of each extracted sample was accomplished for the presence of pyrrole group (Fig. 2b). The FT-IR spectra of extracted samples in the range of $4000-350 \mathrm{~cm}^{-1}$ revealed vibration band at (i) $\sim 3470 \mathrm{~cm}^{-1}$ for pyrrole ring in 40 samples that correlates with $R_{f}$ value of 0.8 using TLC analysis, (ii) $500-800 \mathrm{~cm}^{-1}$ confirmed the presence of chlorine moiety and (iii) 1530 and $1375 \mathrm{~cm}^{-1}$ verified the existence of nitro group only in 15 samples. Consequently, negative test of ferric chloride for nitro group in 15 samples also suggested the presence of PRN (Arima et al. 1964). 
The retention time of HPLC chromatogram spotted at $27.5 \mathrm{~min}$ in all 15 samples (de Souza and Raaijmakers 2003). Among these, only 05 cell free methanol extract of each had shown comparatively significant percent area of peak obtained at 27.5 min from bacterial strains namely, TW-3, TO-2, M-11, M-2 and KMB and hence, selected further for extracellular production of PRN. The methanolic extracts of two bacterial strains, TW-3 and TO-2 were characterised by mass spectrophotometry. The LCMS analysis showed a main peak at $\mathrm{m} / \mathrm{z}=256.232$ and 256.121 for TW-3 and TO-2 samples, respectively (Fig. 3a-b), thus, indicated the presence of PRN. The GC analysis of both samples from both isolates TW-3 and TO-2 also showed highest peak at RT 10.6 min (Fig. 4) for PRN while remaining peak represented derivatives. Furthermore, GCMS analysis of the extract of bacterial cultures TO-2 and TW-3 showed fragments ion at $\mathrm{m} / \mathrm{z}=$ 166 which confirmed the PRN like GCMS chromatogram of extracted sample from wild-type Burkholderia lata 383 reported earlier for PRN (Schmidt et al. 2009).

\section{Antagonistic activity at PRN extracts against F. oxysporum MTCC 9913}

The samples (40) verified with TLC were tested for antagonistic activity against $F$. oxysporum MTCC 9913. Of these, only 32 extracted samples had shown 13-27 mm diameter of zone of inhibition around the wells after 8 days, exhibiting phyto-protecting competence against $F$. oxysporum. However, extracted sample of isolates TW-3, TO-2, KMB, M-2 and M-11 displayed significant inhibitory action against growth of $F$. oxysporum with 27, 25, 17, 13 , and 15 mm of zone of inhibition, respectively (Fig. 5a-b), whereas others were in the range of 11-14 mm in diameter. These results agree with earlier observations (Chernin et al. 1996; de Souza and Raaijmakers 2003; Huang et al. 2018). Apart from suppression of mycelial growth; conidial germination of F. oxysporum was undetected even after 10 days in the present study, indicating cessation of sporulation possibly due to more active phenyl-pyrrole component in methanolic extracted samples (Kilani and Fillinger 2016). These results eventually suggest key role of rhizobacterial isolates in suppressive of phytopathogen by PRN in alkaline and saline soil.

\section{S rRNA and prn coding gene sequencing}

The partial 16S rRNA gene sequence (1.4-1.5 kb) of five bacterial isolates TW-3, TO-2, M-2, M-11 and KMB were amplified with PCR and sequences were searched for similarity using BLAST analysis (Table S1). The search analysis revealed $99 \%$ similarity of the bacterial strain TW-3, TO-2, M-2, M-11 and KMB with Serratia marcescens, Serratia nematodiphila, Enterobacter spp., Brevibacillus parabrevis and Stenotrophomonas rhizophila, respectively and NCBI GenBank database accession numbers of KY800456, KY800457, KY800455, KY800454 and KY800458, respectively (Fig. 6a and Fig. S1a). The bacterial isolate TW-3, TO-2, M-2, M-11 and KMB were deposited in culture collection centers with number [(i) NCIM 5696, (ii) NCIM 5695 and MTCC 12894 , (iii) NCIM 5716, (iv) MTCC 12893, (v) MTCC 12898], respectively. The preliminary biochemical characteristics of selected bacterial strains S. marcescens TW-3 and S. nematodiphila TO-2 was ascertained using Vitek-2 system (Version 07.01) on Gram negative (GN) card (Table S2b). The results also showed $99 \%$ probability and excellent confidence level with S. marcescens. Table S2a summarizes utilization of carbohydrates, sugars and various carbon sources by all five bacterial strains. The phylogenetic relationship of rhizospheric isolates was inferred and constructed based on available 16S rRNA sequences from NCBI database using MEGA 7.0 software tool (Kumar et al. 2016). The taxonomic position of five bacterial isolates is shown in the phylogenetic tree (Fig. $6 \mathrm{~b}$ ). The nucleotide sequences of bacterial isolates were aligned and inferred for the evolutionary history using the neighbor-joining method (Saitou and Nei 1987). Neighborjoining tree based on 16S rRNA gene sequences of rhizobacterial isolates showing the positions of the isolate TW-3 (a), TO-2 (b), M-2 (c), M-11 (d) and KMB (e) with Serratia marcescens, Serratia nematodiphila, Enterobacter spp., Brevibacillus parabrevis and Stenotrophomonas rhizophila expressed as replications. Bar 0.02 substitution per nucleotide position. The optimal tree with the sum of branch length of 0.27687301 was drawn. The percentage of replicate tree in which the associated taxa clustered together in the bootstrap test with 1000 replicates were shown next to the branches (Felsenstein 1985; Felsenstein and Kishino 1993) to assess the reproducibility of clades in the inferred phylogenies. The trees were drawn to the scale, with branch lengths in the same units as those of the evolutionary distances used to infer the phylogenetic tree. The evolutionary distances were computed using the Maximum Composite Likelihood method (Felsenstein and Kishino 1993) and were in the units of the number of base substitutions per site. The analysis involved 8 nucleotide sequences. All positions containing gaps and missing data were eliminated. There were a total of 1461 positions in the final dataset. Of these, Serratia marcescens was reported earlier for PRN production (Purkayastha et al. 2018). The occurrence of extracellular PRN from other rhizobacterial species were reported for the first time in this study.

The bacterial isolates were investigated for the presence of characteristic prnD coding gene by PCR based amplification using primer that have been derived from conserved region of prnD gene identification by de Souza and Raaijmakers (2003). The electrophoretic gel image of PCR amplified product (Fig. 6c) showed distinct bands in Lane 1 and 2 whereas, lane 3 and 5 showed multiple bands and Lane 4 exposed weak single band. Hence, the gel extraction of PCR products was carried out for the band present in the range of 700-800 bp and taken for DNA sequencing (Fig. S1b). However, these gained gene sequences have shown 99\% similarity with putative NADPH dependent FMN reductases present in complete genome of S. marcescens after BLASTn which didn't match with targeted prnD gene. Hence, translated nucleotide query sequence of both isolates was checked using BLASTx against protein data bank and showed gene sequences are belonging to FMN reductase superfamily. As per the Lee and Zhao (2005) for in vitro activity of prnD from Pseudomonas fluorescens Pf-5 required NADPH and FMN molecule. The study revealed biochemical organization of PrnD system where flavoprotein reductase accepts electron from NADPH and transfer to PrnD. Then, the reduced PrnD catalyses oxidation reaction and convert aminopyrrolnitrin to pyrrolnitrin which mimics with FAD reductases encoded by prnF. Thus, suggest the presence of prn gene which possibly codes for the supply of reduced flavin during enzymatic reactions.

Both prnF and prnD proposed to form two component oxygenase systems, wherein prnF provides pool of reduced flavin to prnD gene function that seems to be required in catalysing unusual arylamine oxidation (Hammer et al. 1997; Ellis 2010; Tiwari et al. 2012).

Initially, PSI BLAST of protein sequence from isolates TW-3 and TO-2 was performed to get position specific scoring matrix for secondary structure of related protein sequences. The BLAST hit of protein sequences from isolates TW-3 and TO-2 showed 100 and $99 \%$ identities with class of NAD(P)H-dependent oxidoreductase protein of Serratia spp. Therefore, gene sequence analysis unambiguously confirmed the capacity of the strains TO-2 and TW-3 to secrete PRN and indicate that the prn gene may be contributing to PRN production. 


\section{Comparative PrnF structure modelling using MODELLER and molecular dynamic simulation and docking}

To investigate the structural basis of the reaction mechanism of PrnF, a homology model of the PrnF was built using crystal structure of the flavin reductase (3SVL) from Escherichia coli K12 that showed maximum identity in BLAST (Fig. 7a). The developed model had shown a dual binding cleft for the NADPH and FMN substrate, like the previous reports (van den Heuvel et al. 2004; Okai et al. 2006; Kim et al. 2008; Tiwari et al. 2012).

The result from ProSA as Z-Score, Verify 3D and ERRAT plot displayed - $6.07,81.48 \%$ and 87.4016 , respectively (Fig. S2a-b). The calculated Ramachandran's plot suggested that $91.0 \%, 7.2 \%, 0.9 \%$ and $0.9 \%$ of the residues in derived model were in the most favored, additional allowed, generously allowed and disallowed regions, respectively. Altogether $98 \%$ of the residues were placed into the combined favored and allowed groups. Thus, PROCHECK and other tools validated the folding integrity of the PrnF model and indicated that the protein structure derived from the $3 S \mathrm{VL}$ template was of higher quality in terms of protein folding. Figure $7 \mathrm{~b}$ shows the distribution of $\otimes$ and $\varphi$ from the Ramachandran's plot for the non-glycine, non-proline residues.

Molecular docking was performed to predict the molecular interactions between NADPH, FMN and amino acid residues of PrnF protein using Autodock, Autodock Vina $^{\mathrm{TM}}$ combined with PyRx ${ }^{\mathrm{T}}$. The molecular docking study revealed that FMN molecule was bound with a groove of the PrnF protein. A single hydrogen bond interaction of FMN with the amino acid residues was observed (Fig. S3a). The pyrophosphate moiety of the FMN molecule was bonded with Isoleucine 25 by carbon-hydrogen bond at $6.38 \AA$. While ribose and adenine moiety of the FMN forms (i) pi-sigma bond interaction (shown in dark pink colour) with Leucine39 (3.96), (ii) alkyl bond (interpreted in light pink) with Proline29 (5.01 Å), Proline 36 (5.01 ̊) and Leucine39 (4.35 ̊) (Fig. S3b). The NAPDH also bound protein by (i) hydrogen bond interaction with nicotinamide ring by VAL 27 (4.06 and 3.84), (ii) alkyl bond nicotinamide ring by VAL27 (4.49 ̊̊), (iii) Pi-

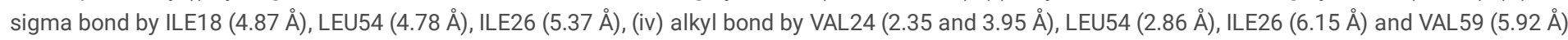
(Fig. S4).

\section{Discussion}

The secretion of PRN in soil by few rhizospheric bacteria has contributed potential role in the (i) suppression of soil to plant pathogens and, (ii) organically driven agricultural practices (Costa et al. 2009). Rhizospheric RJ soil appeared strong brown coloured, with intense dried cracks, while RD soil seems to be dark red to black in colour, possibly due to high iron content. The alkalinity and salinity probably served as key determinants for the occurrence of rhizobacteria in soil to produce PRN (Garbeva et al. 2004) and hence, rhizobacteria application to crop has emerged out as preferred eco-friendly strategy to control phytopathogens compared to the synthetic chemical fungicides.

The rhizobacteria belonging to the genus Serratia was found in root exudates of plants that had affinity towards tryptophan. The root exo-metabolite contains tryptophan in detectable amount in radish root exudates, but, the in vivo concentration of PRN could be produced from available tryptophan is within the range required for fungal inhibition. Hence, secretion of PRN is always in limited quantity than other bacterial metabolites. Interestingly, the previous report had shown that bacterial cell retains PRN inside the cell more than exterior (Roitman et al. 1990) and hence, in vitro antibiosis was examined with supernatant to select efficient rhizobacteria against a test phytopathogen F. oxysporum. Antagonistic activity towards targeted phytopathogen was demonstrated in $23.42 \%$ bacterial culture extracts. The significant suppression of fungal development was seen with cell free broth, indicating extracellular secretion of antibiotics by rhizobacterial isolates. About, 72.22\% Serratia species had displayed antifungal activity due to PRN secretion (Kalbe et al. 1996). Serratia marcescens (Kim et al. 2008) also, IC1270 and IC14 of S. plymuthica strains reported antagonistic activity due to secretion of PRN (Meziane et al. 2006; Liu et al. 2007), indicating that present study is in line with earlier reports.

The presence of pyrrole ring in the cell free broth was detected using Ehrlich reagent ( $2 \% \mathrm{p}$-dimethyl-amino-benzaldehyde), where reaction occurs with available a-hydrogen of pyrrole in boron trifluoride methanolic complex (Mattocks 1967). Ehrlich reagent in ethanolic hydrochloride formed weak and unstable colour complex that fade instantly during TLC analysis. Of 111 rhizobacterial isolates, only solvent extract of 15 bacterial strains demonstrated the presence of pyrrole ring and nitro group using FTIR and HPLC. The analytical tools revealed PRN secretion only in $13.5 \%$ rhizobacteria isolates possibly due to (i) undetectable secretion and (ii) absence of metabolic system to synthesize the compound from tryptophan. PRN from microbes was detected only in Dtryptophan amended MS medium and (El-Banna and Winkelmann 1998) indicated L-tryptophan had no effect on PRN production possibly tryptophan enters the cell quickly and utilized for protein synthesis. The initial characterization with UV, TLC, Ehrlich's reaction test, IR and HPLC of metabolites secreted from various genera of bacteria demonstrated that the secretion of PRN is not restricted to Pseudomonas or Burkholderia. The chromatography (GC and HPLC) and mass spectroscopy (LCMS and GCMS) confirmed extracellular secretion of PRN from S. marcescens TW-3 and S. nematodiphila TO-2. PRN was isolated from bacterial cell extract (Arima et al. 1964; de Souza and Raaijmakers 2003) but, extracellular PRN was recorded up to minimum $5 \%$ secretion as contrast to the Roitman et al. (1990) who reported $98 \%$ phenylpyrrole present in the cell extract while only $1 \%$ found in the supernatant. $B$. cepacia in monosodium glutamate medium at $27^{\circ} \mathrm{C}$ for 5 days showed very low yield of PRN $\left(0.54 \mu \mathrm{gml}^{-1}\right)$ by intracellular secretion (El-Banna and Winkelmann 1998). These findings demonstrated that PRN production is not unique to the genus Pseudomonas and our study uncovers PRN production by newer rhizospheric bacteria possibly contributing to selective antagonistic activity against fungal phytopathogens (Garbeva et al. 2004).

The preliminary morphology and 16S rRNA sequencing remarkably showed prevalence of rhizobacteria that are still unknown for the presence of phenylpyrrole/PRN-producers. Hence, prnD was used as a marker gene for screening of PRN producer strains. For this, five bacterial isolates screened initially for the PRN were detected for the presence of prnD with specific primers (PRND1 and PRND2) developed from conserved sequences (de Souza and Raaijmakers 2003). PCR amplification of prnD in three isolates namely, S. rhizophila KMB, Enterobacter spp. M-2 and B. parabrevis M-11 revealed absence of a distinct band, suggesting unsuccessful amplification of prnD gene (Fig. 6c). It may be possibly due to (i) dissimilarity of prnD gene sequences from that of Pseudomonas spp. or may harbour distant prnD gene and (ii) mismatches between the primers used and DNA template of respective strain i.e. primers specificity probably restricted to Pseudomonas and Burkholderia spp. only (de Souza and Raaijmakers 2003; Garbeva et al. 2004; Costa et al. 2009) and

Page $7 / 19$ 
necessitate to optimize PCR or RT PCR with new specific primers for the occurrence of prnD coding genes in rhizobacteria KMB, M-2 and M-11 strains. These results agree with earlier report (Costa et al. 2009) where two Serratia strains 5.1R and 5.3R were not amplified with prnD. In the present study, both isolates TO-2 and TW-3 have demonstrated PRN production with chemical tools and, shown distinct band after PCR amplification but, the gene sequences (KY867430 and KY867431) (Fig. S1B) were not matching with prnD gene after BLASTn analysis. Although, rhizobacteria TO-2 and TW-3 have shown to secrete PRN by analytical tools but undetected for prnD may be due to polymorphic nature of prnD sequences (Costa et al. 2009). However, these prn gene sequence have shown $99 \%$ similarity with putative NADPH dependent FMN reductases present in complete genome of $S$. marcescens after BLASTn. Additionally, BLASTx revealed that the gene sequences belong to FMN reductase superfamily and thus, suggest the presence of prn gene which possibly codes for the supply of reduced flavin during enzymatic reactions.

The earlier reports suggested the role of FAD dependent prnF to supply the reduced flavin for functioning of prnD as product in PRN secretion (Hammer et al 1997; Tiwari et al. 2012). However, functional or structural differences between the FMN-dependent and FAD-dependent enzyme systems were undetected (Ellis 2010). Hence, the query sequences (KY867430 and KY867431) in the present study were considered as prnF gene. On the contrary, earlier study had shown that $p r n F$ is non-specific and not directly involved in PRN biosynthesis (van Pee 2012) but, it is required for prnD to function and enhance PrnDs activity (Hammer et al. 1997; Lee et al. 2005; van Pee 2012). The bacterial DNA lacking prnF but having prnD gene may lose their ability to form PRN and thereof accumulate aminopyrrolnitrin (van Pee 2012). Aminopyrrolnitrin oxygenase (prnD) catalyses unusual arylamine oxidation which is only characterized example of arylamine N-oxygenases involved in arylnitro group formation (Lee and Zhao 2007) As stated earlier, monooxygenases are the flavoprotein enzyme that carries two reactions on a single polypeptide chain. The reduction of flavins followed by the transfer of reduced flavins to the oxygenase component by flavindependent reductases is the common reaction observed in two-component oxygenase family. Reduced form of flavin mononucleotide (FMN), flavin adenine dinucleotide (FAD), and riboflavin by $\mathrm{NAD}(\mathrm{P}) \mathrm{H}$ are required to activate oxygen by the terminal oxygenases. However, the earlier study suggests reductase involved in two-component oxygenase of Pseudomonas fluorescens Pf-5 prefers FAD specific for NADH (Hammer et al. 1997) In addition, it has shown that the purified PrnD of $P$. fluorescens Pf-5 requires NADPH, FMN and flavin reductases for its functional expression in in vitro. The expression of prnF with prnD showed 15 -fold higher activity of prnD than that of E. coli BL21 carrying only prnD (Lee et al. 2005). Moreover, single gene encoding an FMN reductase ( $p r n F$ ) express in heterologous hosts may not predict the role in PRN secretion. It necessitates coexpression with prnD and to this, requires (i) specific primers developed from conserved sequences of Serratia spp. for prnD, (ii) amplification of fragments with Serratia that produce PRN and, (iii) gene loci and its regulation in Serratia spp. The present study provided distinct reaction of PRN biosynthesis where NADPH dependent FMN reductase is involved to form reduced flavin in Serratia spp. FMN-dependent monooxygenases have been characterized in antibiotic synthesis in several Streptomyces spp. (Thibaut et al. 1995; Filisetti et al. 2003; Volton et al. 2008). As per the earlier reports, (i) reductases from the two-component system is specific for FMN, but monooxygenase may utilize either FMN or FAD also, (ii) FMN reductase differed in their specificity for NADH and NADPH (Sucharitakul et al. 2005; Ellis 2010) supporting to NADPH dependent FMN in single reaction for PRN secretion. This study signifies the role of PrnF in PRN biosynthesis (Tiwari et al. 2012)

The functional characterization of a studied protein sequence was facilitated by developing three-dimensional (3D) structure of protein using comparative or homology modelling which provided a structure related to one known protein. PrnF is superimposed with reductase part of the Escherichia coli K12 (3SVL). The objective to perform molecular docking is to (i) gain optimized conformation of PrnF, FMN and NADPH i.e. ligand-receptor complex with less binding energy and (ii) predict binding parameters of ligand-protein complex. The docking simulation with modelled PrnF has shown that several amino acids are in close contacts with the ligands i.e. FMN and NADPH (Fig. 7c). Overall, FMN is bounded with protein through hydrogen bond along with van der Waals, carbonhydrogen, Pi-Sigma and alkyl bonds (Fig. S3b). The isoalloxazine ring of FMN probably fixed in the deep groove of the protein whereas NADPH restricted at wide groove with compact bonded conformation with nicotinamide ring where, binding capacity of protein-NADPH and protein FMN was - 5.7 and - 5.0, respectively.

Theoretical indications of the PrnF reductase in the two-component aryl amine oxygenase system allows to continue more detailed investigation of this system by genetical-structural characterization with protein engineering and interaction studies. Also, PRN protein model suggests highly restricted conformational space in active site and necessitate to relate the gene with various physiological scenario, interaction of biomolecules with enzymes. These comparative models provide the value of domains/proteins belonging to Serratia spp. in the stereoselective synthesis of pharmaceutically important drugs (Peng et al. 2014; Bai et al. 2015; Liu et al. 2018). In conclusion, preliminary molecular modelling analysis represents the basic study on prnF and further detailing of prnF with FMN and NADPH may pave more insight on two component arylamine oxygenase system in PRN production among rhizobacteria.

\section{Conclusion}

The present study demonstrated that PRN secretion is not restricted for Pseudomonas, Burkholderia and Serratia spp. The final step of pyrrolnitrin in Serratia spp., flavin (FMN) reductase transfers the electron from NADPH to the aminopyrrolnitrin oxidase. Molecular docking represents the basic interaction with FMN and NADPH on PrnF and further detailing may pave more insight on two component arylamine oxygenase system in PRN production. Beside these, the analytical characterization of solvent extracts from Brevibacillus parabrevis Stenotrophomonas rhizophila, Enterobacter spp., showed the presence of pyrrolnitrin but detail molecular study of these new genera of PRN secreters are obligatory.

\section{Abbreviations}

\section{PRN}

Pyrrolnitrin; KB:King's B Medium; TBT:Tryphan Blue Tetracycline; MS:Mineral Salt; PDA:Potato Dextrose Agar; OD:Optical Density; IR:Infra-Red; UV:Ultra-Violet; TLC:Thin layer chromatography; LC:Liquid chromatography; GC:Gas Chromatography; MS:Mass Spectroscopy; MTCC:Microbial Type Culture Collection; NCIM:National Collection of Industrial Microorganisms; PCR:Polymerase Chain Reaction; DNA:Deoxyribonucleic acid; BLAST:Basic Local Alignment Search Tool; NCBI:National Center for Biotechnology Information; RT:Retention Time. 


\section{Declarations}

\section{ETHICS APPROVAL AND CONSENT TO PARTICIPATE}

Not applicable

\section{CONSENT FOR PUBLICATION}

The manuscript is original; no part of the manuscript has been published before, nor is any part of it under consideration for publication.

\section{AVAILABILITY OF DATA AND MATERIALS}

The datasets used and/or analysed during the current study are available from the corresponding author on reasonable request.

\section{COMPETING INTERESTS}

Both authors are disclosing that there isn't any actual and potential interest including any financial, personal or organizations and the submitted work could not be inappropriately or be perceived to influence.

\section{FUNDING}

Not applicable

\section{AUTHORS CONTRIBUTIONS}

SP: Design and conduct the experiments, writing original draft; AC: Conceptualization, supervision, writing-review and editing. Both authors read and approved the final manuscript

\section{ACKNOWLEDGEMENTS}

The authors acknowledge the infrastructural grant provided through UGC-SAP-DRS (III) from University Grants Commission, New Delhi and DST-FIST from Department of Science and Technology, New Delhi to the School of Life Sciences, Kavayitri Bahinabai Chaudhari North Maharashtra University, Jalgaon. Ms. Shraddha acknowledges the financial support through UGC-BSR fellowship from University Grant Commission (UGC), New Delhi. The authors are thankful to (i) Ashwin Kumar Bhaverkar, for bacterial identification by BioMerieux VITEK-2 Compact and, (ii) Hassan Rasouli MBRC, Kermanshah University of Medical Science, Kermanshah, Iran for extending guidance on molecular docking.

\section{References}

1. Ahmad F, Ahmad I, Khan M (2008) Screening of free-living rhizospheric bacteria for their multiple plant growth promoting activities. Microbiol Res 163:173-181. https://doi.org/10.1016/j.micres.2006.04.001

2. Arima K, Imanaka H, Kousaka M, Fukuta A, Tamura G (1964) Pyrrolnitrin, a new antibiotic substance, produced by Pseudomonas. Agric Biol Chem 28:575-576. https://doi.org/10.1080/00021369.1964.10858275

3. Bai F, Dai L, Fan J, Truong N, Rao B, Zhang L, Shen Y (2015) Engineered Serratia marcescens for efficient (3R)-acetoin and (2R, 3R)-2, 3-butanediol production. J Ind Microbiol Biotechnol 42:779-786. 10.1007/s10295-015-1598-5

4. Barazani O, Friedman J (1999) Is IAA the major root growth factor secreted from plant-growth-mediating bacteria? J Chem Ecol 25:2397-2406. https://doi.org/10.1023/A:1020890311499

5. Bhardwaj V, Gumber D, Abbot V, Dhiman S, Sharma (2015) P Pyrrole a resourceful small molecule in key medicinal hetero aromatics. RSC Advances 5:15233-15266. https://doi.org/10.1039/C4RA15710A

6. Burkhead K, Schisler D, Slininger P (1994) Pyrrolnitrin production by biological control agent Pseudomonas cepacia B37w in culture and in colonized wounds of potatoes. Appl Environ Microbiol 60:2031-2039

7. Chernin L, Brandis A, Ismailov Z, Chet I (1996) Pyrrolnitrin production by an Enterobacter agglomerans strain with a broad spectrum of antagonistic activity towards fungal and bacterial phytopathogens. Curr Microbiol 32:208-212. https://doi.org/10.1007/s002849900037

8. Costa R, van Aarle I, Mendes R, van Elsas J (2009) Genomics of pyrrolnitrin biosynthetic loci: Evidence for conservation and whole-operon mobility within Gram negative bacteria. Environ Microbiol 11:159-175. 10.1111/j.1462-2920.2008.01750.x

9. Dallakyan S, Arthur J (2015) Small-molecule library screening by docking with PyRx. In: Chemi. Biol. Humana Press, New York, pp $243-250$. https://doi.org/10.1007/978-1-4939-2269-7_19

10. 10.1111/j.1574-6941.2003.tb01042.x de Souza J, Raaijmakers J (2003) Polymorphisms within the prnD and p/tC genes from pyrrolnitrin and pyoluteorin-producing Pseudomonas and Burkholderia spp. FEMS Microbiol Ecol 43: 21-34. 10.1111/j.1574-6941.2003.tb01042.x

11. di S Roberto, Costi R, Artico M, Massa S, Lampis G, Deidda D, Pompei R (1998) Pyrrolnitrin and related pyrroles endowed with antibacterial activities against Mycobacterium tuberculosis. Bioorganic Med Chem Lett 8: 2931-2936. 10.1016/s0960-894 × (98)00526-5

12. El-Banna N, Winkelmann G (1998) Pyrrolnitrin from Burkholderia cepacia: Antibiotic activity against fungi and novel activities against streptomycetes. $J$ Appl Microbiol 85:69-78. 10.1046/j.1365-2672.1998.00473.x 
13. Ellen L, Eisenhauer N, Rall B, Allan E, Roscher C, Scheu S, Jousset A (2012) Plant diversity improves protection against soil borne pathogens by fostering antagonistic bacterial communities. J Ecol 100:597-604. https://doi.org/10.1111/j.1365-2745.2011.01940.x

14. Ellis H (2010) The FMN-dependent two-component monooxygenase systems. Arch Biochem Biophys 497:1-12. https://doi.org/10.1016/j.abb.2010.02.007

15. Felsenstein J (1985) Confidence limits on phylogenies: An approach using the bootstrap. Evolution 39:783-791. 10.2307/2408678

16. Felsenstein J, Kishino H (1993) Is there something wrong with the bootstrap on phylogenies? A reply to Hillis and. Bull Syst Biol 42:193-200. https://doi.org/10.1093/sysbio/42.2.193

17. Filisetti L, Fontecave M, Niviere V (2003) Mechanism and substrate specificity of the flavin reductase ActVB from Streptomyces coelicolor. J Biol Chem 278:296-303. 10.1074/jbc.M209689200

18. Fiser A, Do R (2000) Modeling of loops in protein structures. Prot Sci 9:1753-1773. 10.1110/ps.9.9.1753

19. Frese M, Sewald N (2014) Enzymatic halogenation of tryptophan on a gram scale. Angew Chem Int Ed 54:298-301. https://doi.org/10.1002/anie.201408561

20. Garbeva P, Voesenek K, Van Elsas J (2004) Quantitative detection and diversity of the pyrrolnitrin biosynthetic locus in soil under different treatments. Soil Bio Biochem 36:1453-1463. https://doi.org/10.1016/j.soilbio.2004.03.009

21. Gerth K, Trowitzsch W, Wray V, Hofle G, Irschik H, Reichenbach H (1982) Pyrrolnitrin from Myxococcus fulvus (myxobacterales). J Antibiot 35:1101-1103. 10.7164/antibiotics.35.1101

22. 10.1007/978-3-662-38441-1_32

Gorman M, Lively DH (1967) Pyrrolnitrin: A new mode of tryptophan metabolism. In: Biosynthesis, Springer-Berlin, Heidelberg, $433-438$. https://doi.org/10.1007/978-3-662-38441-1_32

23. Gupta PK (1999) Soil, plant, water and fertilizer analysis. Agro Botanica

24. Hagedorn C, Gould W, Bardinelli T, Gustavson D (1987) A selective medium for enumeration and recovery of Pseudomonas cepacia biotypes from soil. Appl Environ Microbio 53:2265-2268. 10.1128/AEM.53.9.2265-2268.1987

25. Hamill R, Elander R, Mabe J, Gorman M (1967) Metabolism of tryptophan by Pseudomonas aureofaciens V: Conversion of tryptophan to pyrrolnitrin. Antimicrob Agents Chemother: 388-396

26. Hammer P, Evensen K, Janisiewicz W (1993) Postharvest control of Botrytis cinerea on cut rose flowers with pyrrolnitrin. Plant Dis 77:283-286. https://doi.org/10.21273/HORTSCI.25.9.1139a

27. Hammer P, Hill D, Lam S, van Pee K, Ligon J (1997) Four genes from Pseudomonas fluorescens that encode the biosynthesis of pyrrolnitrin. Appl Environ Microbiol 63:2147-2154

28. 10.1002/anie.199720121

Hohaus K, Altmann A, Burd W, Fischer I, Hammer P, Hill D, Ligon J, van Pee K (1997) NADH-dependent halogenases are more likely to be involved in halometaolite biosynthesis than haloperoxidases. Angew Chem 36th Int edn. 2012-2013. https://doi.org/10.1002/anie.199720121

29. Hong K, Kim Y, Anderson A, Kim Y (2014) Proteomic analysis of a global regulator GacS sensor kinase in the rhizobacterium Pseudomonas chlororaphis 06. Plant Pathol J 30:220. 10.5423/PPJ.NT.02.2014.0012

30. Huang R, Feng Z, Chi X, Sun X, Lu Y, Zhang B, Lu R, Luo W, Wang Y, Miao J, Ge Y (2018) Pyrrolnitrin is more essential than phenazines for Pseudomonas chlororaphis G05 in its suppression of Fusarium graminearum. Microbiol Res 215:55-64. https://doi.org/10.1016/j.micres.2018.06.008

31. Jespers ABK, Maarten A De Waard (1995) Effect of fenpiclonil on phosphorylation of glucose in. Fusarium sulphureum Pest Sci 44:167-175. https://doi.org/10.1002/ps.2780440210

32. Jones JB Jr (2001) Laboratory guide for conducting soil tests and plant analysis. CRC press

33. Kalbe C, Marten P, Berg G (1996) Strains of the genus Serratia as beneficial rhizobacteria of oilseed rape with antifungal properties. Microbio Res 151:433-439. https://doi.org/10.1016/S0944-5013(96)80014-0

34. Kamilova F, Kravchenko L, Shaposhnikov A, Azarova T, Makarova N, Lugtenberg B (2006) Organic acids, sugars, and L-tryptophane in exudates of vegetables growing on stonewool and their effects on activities of rhizosphere bacteria. Mol Plant Microbe Interact 19:250-256. 10.1094/MPMI-19-0250

35. Kefford N, Brockwell J, Zwar J (1960) The symbiotic synthesis of auxin by legumes and nodule bacteria and its role in nodule development. Aust J Biol Sci 13:456-467. 10.1071/bi9600456

36. Kessler W, Heilmaier H, Kreuzer P, Shen J, Filser M, Filser J (1990) Spectrophotometric determination of pyrrole-like substances in urine of rat and man: An assay for the evaluation of 2,5-hexanedione formed from n-hexane. Arch Toxicol 64:242-246. 10.1007/BF02010731

37. Keum Y, Lee Y, Lee Y, Kim J (2009) Effects of nutrients on quorum signals and secondary metabolite productions of Burkholderiasp. O33. J Microbiol Biotechnol 19:1142-1149. 10.4014/jmb.0901.465

38. $10.3389 /$ fmicb. 2016.02014 Kilani J, Fillinger S (2016) Phenylpyrroles: 30 years, two molecules and (nearly) no resistance. Front Microbiol 7: 2014. 10.3389/fmicb.2016.02014

39. Kim S, Hisano T, Iwasaki W, Ebihara A, Miki K (2008) Crystal structure of the flavin reductase component (HpaC) of 4-hydroxyphenylacetate 3monooxygenase from Thermus thermophilus HB8: Structural basis for the flavin affinity. Proteins: Struct Funct Bioinf 70:718-730. 10.1002/prot.21534

40. Kirner S, Hammer EP, Steven D, Annett A, Fischer I, Weislo L, Lanahan M, van Pee KH, Ligon J (1998) Functions encoded by pyrrolnitrin biosynthetic genes from Pseudomonas fluorescens. J Bact 180:1939-1943. https://doi.org/10.1128/JB.180.7.1939-1943.1998 
41. Kravchenko L, Azarova T, Makarova N, Tikhonovich I (2004) The effect of tryptophan present in plant root exudates on the phytostimulating activity of rhizobacteria. Microbio 73:156-158. https://doi.org/10.1023/B:MICl.0000023982.76684.9d

42. Kumar S, Stecher G, Tamura K (2016) MEGA7: Molecular Evolutionary Genetics Analysis version 7.0 for bigger datasets. Mol Biol Evol 33:1870-1874. 10.1093/molbev/msw054

43. Lee J, Simurdiak M, Zhao H (2005) Reconstitution and characterization of aminopyrrolnitrin oxygenase: A Rieske N-oxygenase that catalyzes unusual arylamine oxidation. J Biol Chem: 36719-36727. 10.1074/jbc.M505334200

44. Lee J, Zhao H (2007) Identification and characterization of the flavin: NADH reductase (PrnF) involved in a novel two-component arylamine oxygenase. J Bacteriol 189:8556-8563. 10.1128/JB.01050-07

45. Ligon J, Hill D, Hammer P, Torkewitz N, Hofmann D, Kempf H, Pee V (2000) Natural products with antifungal activity from Pseudomonas biocontrol bacteria. Pest Manag Sci 56: 688-695. https://doi.org/10.1002/1526-4998(200008)56:8<688:AID-PS186>3.0.C0;2-V

46. Liu J, Kuan Y, Tsou Y, Lin T, Hsu W, Yang M, Lin J, Wang W (2018) Structure-guided design of Serratia marcescens short-chain dehydrogenase/reductase for stereoselective synthesis of (R)-phenylephrine. Sci Rep 8:2316. 10.1038/s41598-018-19235-y

47. Liu S, Hu X, Lohrke S, Baker C, Buyer J, de Souza J, Roberts D (2007) Role of sdhA and pfkA and catabolism of reduced carbon during colonization of cucumber roots by Enterobacter cloacae. Microbio 1:3196-3209. 10.1099/mic.0.2006/005538-0

48. Liu X, Bimerew M, Ma Y, Muller H, Ovadis M, Eberl L, Berg G, Chernin L (2007) Quorum-sensing signaling is required for production of the antibiotic pyrrolnitrin in a rhizospheric biocontrol strain of Serratia plymuthica. FEMS Microbio Let 270:299-305. 10.1111/j.1574-6968.2007. 00681.x

49. Mattocks A (1967) Spectrophotometric determination of unsaturated pyrrolizidine alkaloids. Anal Chem 39:443-447. https://doi.org/10.1021/ac60248a006

50. Meziane H, Gavriel S, Ismailov Z, Chet I, Chernin L, Hofte M (2006) Control of green and blue mould on orange fruit by Serratia plymuthica strains IC14 and IC1270 and putative modes of action. Post Biolo Techn 39:125-133. https://doi.org/10.1016/j.postharvbio.2005.10.007

51. Morris D, Johnson C (1987) Regulation of auxin transport in pea (Pisum sativum L.) by phenylacetic acid: Inhibition of polar auxin transport in intact plants and stem segments. Planta172: 408-416. 10.1007/BF00398671

52. Nakatsu C, Straus N, Wyndham R (1995) The nucleotide sequence of the Tn5271 3-chlorobenzoate 3, 4-dioxygenase genes (cbaAB) unites the class IA oxygenases in a single lineage. Microbiol 141:485-495. 10.1099/13500872-141-2-485

53. 10.1371/journal.pone.0123184

Nandi M, Selin C, Brassinga AKC, Belmonte MF, Fernando WD, Loewen PC, De Kievit PR (2015) Pyrrolnitrin and hydrogen cyanide production by Pseudomonas chlororaphis strain PA23 exhibits nematicidal and repellent activity against Caenorhabditis elegans. PloS one10: e0123184. https://doi.org/10.1371/journal.pone.0123184

54. Neubauer P, Widmann C, Wibberg D, Schröder L, Frese M, Kottke T, Kalinowski J, Niemann H, Sewald N (2018) A flavin-dependent halogenase from metagenomic analysis prefers bromination over chlorination. PloS one 13:e0196797. https://doi.org/10.1371/journal.pone.0196797

55. Nose M, Arima K (1969) On the mode of action of a new antifungal antibiotic, pyrrolnitrin. J Antibiot 22:135-143. 10.7164/antibiotics.22.135

56. Okai M, Kudo N, Lee W, Kamo M, Nagata K, Tanokura M (2006) Crystal structures of the short-chain flavin reductase HpaC from Sulfolobus tokodaii strain 7 in its three states: NAD (P)+-free, NAD+-bound, and NADP+-bound. Biochem 45:5103-5110. https://doi.org/10.1021/bi052313i

57. Pandya S, lyer P, Gaitonde V, Parekh T, Desai A (1999) Chemotaxis of Rhizobium sp. S2 towards Cajanus cajan root exudate and its major components. Curr Microbiol 38:205-209. 10.1007/pl00006788

58. Parry R, Nishino S, Spain J (2011) Naturally occurring nitro compounds. Nat Prod Rep 28:152-167. 10.1039/c0np00024h

59. Pawar S, Chaudhari A (2019) Pyrrolnitrin from rhizospheric Serratia marcescens NCIM 5696: optimization of process parameters using statistical tools and seed-applied bioprotectants for Vigna radiata (L.) against Fusarium oxysporum MTCC 9913. Appl Biochem Biotech 190(3):803-825. https://doi.org/10.1007/s12010-019-03123-w

60. Pawar S, Chaudhari A, Prabha R, Shukla R, Singh DP (2019) Microbial pyrrolnitrin: natural metabolite with immense practical utility. Biomolecules 9:443. https://doi.org/10.3390/biom9090443

61. Peng G, Kuan Y, Chou H, Fu T, Lin J, Hsu W, Yang M (2014) Stereoselective synthesis of (R)-phenylephrine using recombinant Escherichia coli cells expressing a novel short-chain dehydrogenase/reductase gene from Serratia marcescens BCRC 10948. J Biotechnol 170:6-9.

10.1016/j.jbiotec.2013.11.011

62. Purkayastha G, Mangar P, Saha A, Saha D (2018) Evaluation of the biocontrol efficacy of a Serratia marcescens strain indigenous to tea rhizosphere for the management of root rot disease in tea. PloS one 13:e0191761. 10.1371/journal.pone.0191761

63. Richard H (2003) The biosynthesis of plant alkaloids and nitrogenous microbial metabolites. Nat Prod Rep 20:494-508. 10.1039/a809393h

64. Roberts D, McKenna L, Lakshman D, Meyer S, Kong H, De Souza J, Lydon J, Baker C, Chung S (2007) Suppression of damping-off of cucumber caused by Pythium ultimum with live cells and extracts of Serratia marcescens N4-5. Soil Biol Biochem 39:2275-2288. 10.1016/j.soilbio.2007.03.029

65. Roitman J, Mahoney N, Janisiewicz W, Benson M (1990) A new chlorinated phenylpyrrole antibiotic produced by the antifungal bacterium Pseudomonas cepacia. J Agric Food Chem 38:538-541. https://doi.org/10.1021/jf00092a044

66. Saitou N, Nei M (1987) The neighbor-joining method: A new method for reconstructing phylogenetic trees. Mol Biol Evol 4:406-425. https://doi.org/10.1093/oxfordjournals.molbev.a040454

67. Sako M, Toshiyuki K, Mihoko T, Yoshifumi M, Akira M, Toshio A, Shigetaka K, Takashi M (2002) Novel photodegradation of the antifungal antibiotic pyrrolnitrin in anhydrous and aqueous aprotic solvents. J Org Chem 67:668-673. https://doi.org/10.1021/jo010619z

68. Sali A, Blundell T (1993) Comparative protein modelling by satisfaction of spatial restraints. J Mol Biol 234:779-815. 10.1006/jmbi.1993.1626

Page $11 / 19$ 
69. Sanchez C, Butovich I, Brana A, Rohr J, Mendez C, Salas J (2002) The biosynthetic gene cluster for the antitumor rebeccamycin: characterization and generation of indolocarbazole derivatives. Chem Bio 9:519-531. 10.1016/s1074-5521(02)00126-6

70. Schmidt S, Blom JF, Pernthaler J, Berg G, Baldwin A, Mahenthiralingam E, Eberl L (2009) Production of the antifungal compound pyrrolnitrin is quorum sensing regulated in members of the Burkholderia cepacia complex. Environ Micro 11:1422-1437. https://doi.org/10.1111/j.1462-2920.2009.01870.x

71. Seibold C, Schnerr H, Rumpf J, Kunzendorf A, Hatscher C, Wage T, Ernyei A, Dong C, Naismith J, van Pee K (2006) A flavin-dependent tryptophan 6halogenase and its use in modification of pyrrolnitrin biosynthesis. Biocat Biotrans 24:401-408. https://doi.org/10.1080/10242420601033738

72. Sucharitakul J, Chaiyen P, Entsch B, Ballou D (2005) The reductase of p-hydroxyphenylacetate 3-hydroxylase from Acinetobacter baumannii requires phydroxyphenylacetate for effective catalysis. Biochem 44:10434-10442. https://doi.org/10.1021/bi050615e

73. Tahat M, Sijam K, Othman R (2010) The role of tomato and corn root exudates on Glomus mosseae spore germination and Ralstonia solanacearum growth in vitro. J Plant Pathol 1:1-12. 10.3923/ijpp.2010.1.12

74. Tandon HLS (2005) Methods of analysis of soils, plants, waters and fertilizer. Fertilizer Development and Consultation Organization, New Delhi

75. Tawara S, Matsumoto S, Hirose T, Matsumoto Y, Nakamoto S, Mitsuno M, Kamimura T (1989) In vitro antifungal synergism between pyrrolnitrin and clotrimazole. J Med Mycol 30:202-210. https://doi.org/10.3314/jjmm1960.30.202

76. Tawaraya K, Horie R, Saito A, Shinano T, Wagatsuma T, Saito K, Oikawa A (2013) Metabolite profiling of shoot extracts, root extracts, and root exudates of rice plant under phosphorus deficiency. J Plant Nutr 36:1138-1159. https://doi.org/10.1080/01904167.2013.780613

77. Thibaut D, Ratet N, Bisch D, Faucher D, Debussche L, Blanche F (1995) Purification of the two-enzyme system catalyzing the oxidation of the D-proline residue of pristinamycin IIB during the last step of pristinamycin IIA biosynthesis. J Bacterial 177:5199-5205. 10.1128/jb.177.18.5199-5205.1995

78. Tiwari M, Singh R, Lee J, Zhao H (2012) Mechanistic studies on the flavin: NADH reductase (PrnF) from Pseudomonas fluorescens involved in arylamine oxygenation. Bioorganic Med Chem Lett 22:1344-1347. https://doi.org/10.1016/j.bmcl.2011.12.078

79. Tripathi R, Gottlieb D (1969) Mechanism of action of the antifungal antibiotic pyrrolnitrin. J Bacteriol 100:310-318

80. Trott O, Arthur J (2010) AutoDock Vina: improving the speed and accuracy of docking with a new scoring function, efficient optimization, and multithreading. J Comput Chem 31:455-461. 10.1002/jcc.21334

81. Valton J, Mathevon C, Fontecave M, Niviere V, Ballou D (2008) Mechanism and regulation of the two-component FMN-dependent monooxygenase ActVAActVB from Streptomyces coelicolor. J Biol Chem 283:10287-10296. 10.1074/jbc.M709730200

82. van den Heuvel R, Westphal A, Heck A, Walsh M, Rovida S, van Berkel W, Mattevi A (2004) Structural studies on flavin reductase PheA2 reveal binding of NAD in an unusual folded conformation and support novel mechanism of action. J Biol Chem 279:12860-12867. 10.1074/jbc.M313765200

83. van Pee K (2001) Microbial biosynthesis of halometabolites. Arch Microbiol 175:250-258. 10.1007/s002030100263

84. van Pee K (2012) Enzymatic chlorination and bromination. Methods Enzymol 516:237-257. https://doi.org/10.1016/B978-0-12-394291-3.00004-6

85. Weisser W, Roscher C, Meyer S, Luo A, Allan E, Beßler H et al (2017) Biodiversity effects on ecosystem functioning in a 15-year grassland experiment: patterns, mechanisms, and open questions. Basic Appl Ecol 23:1-73. 10.1016/j.baae.2017.06.002

86. Yaryura P, Leon M, Correa O, Kerber N, Pucheu N, Garcia A (2008) Assessment of the role of chemotaxis and biofilm formation as requirements for colonization of roots and seeds of soybean plants by Bacillus amyloliquefaciens BNM339. Curr Microbiol 56:625-632. 10.1007/s00284-008-9137-5

87. Zuckerkandl E, Pauling L (1965) Evolutionary divergence and convergence in proteins. Evolv Gen Prot 97:97-166. https://doi.org/10.1016/B978-1-48322734-4.50017-6

\section{Figures}


Fig. 1: a)

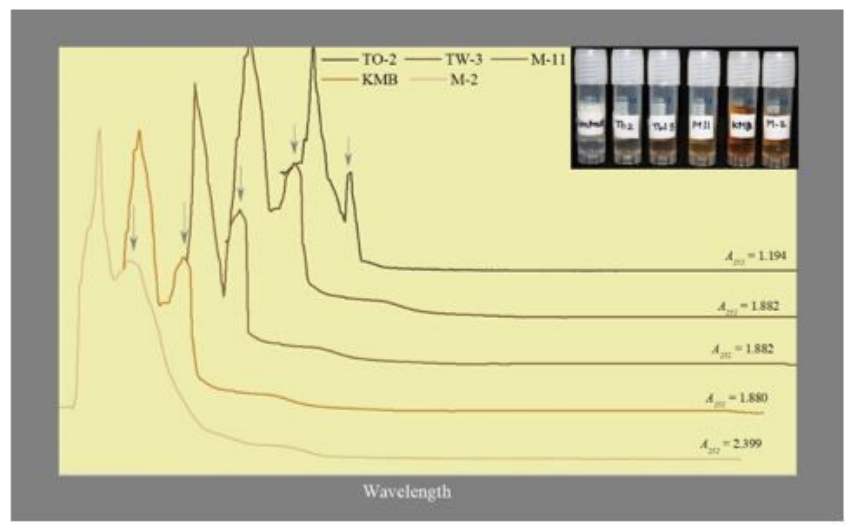

b)

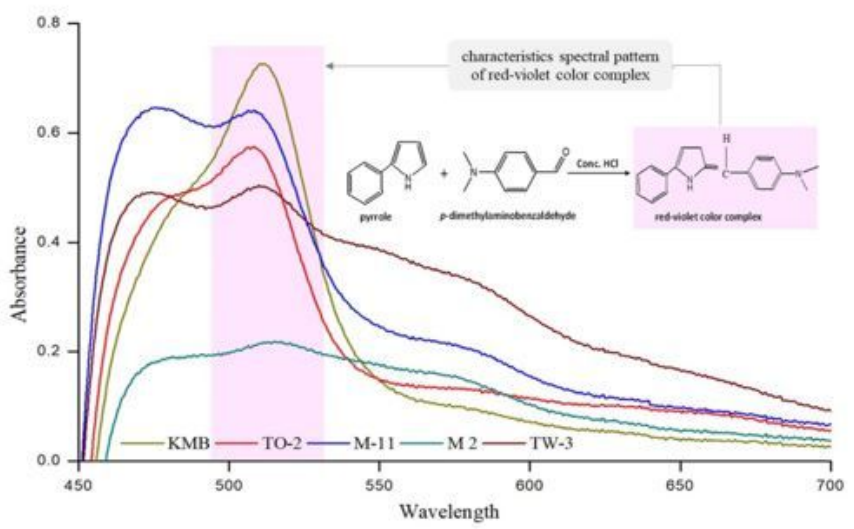

\section{Figure 1}

a) UV spectral scan of methanol extracted samples from rhizobacterial isolates of TO-2, TW-3, M-11, KMB and M-2. UV shows two major peaks while arrow specified peak at $252 \mathrm{~nm}$. b) Absorption spectral pattern of bacterial extracts in the presence of Ehrlich reagent after 5 min exposure for pyrrole detection. Redviolet color complex and characteristics spectral pattern of complex shown in color band. 


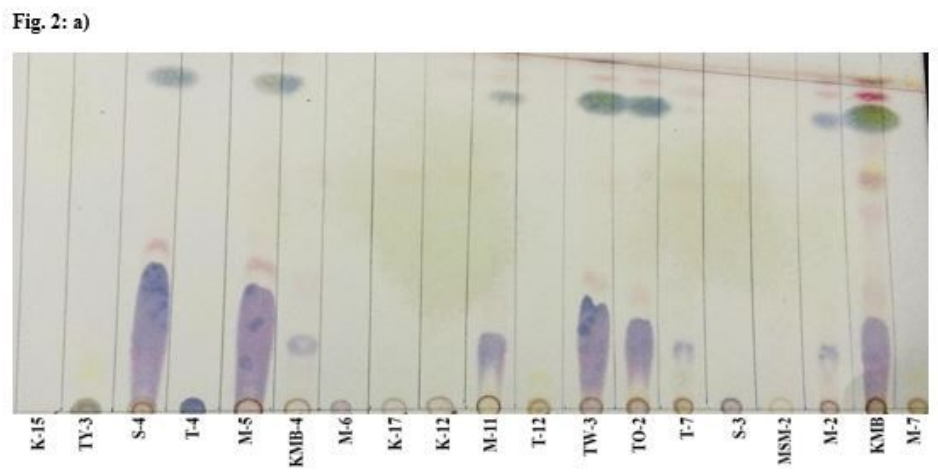

b)

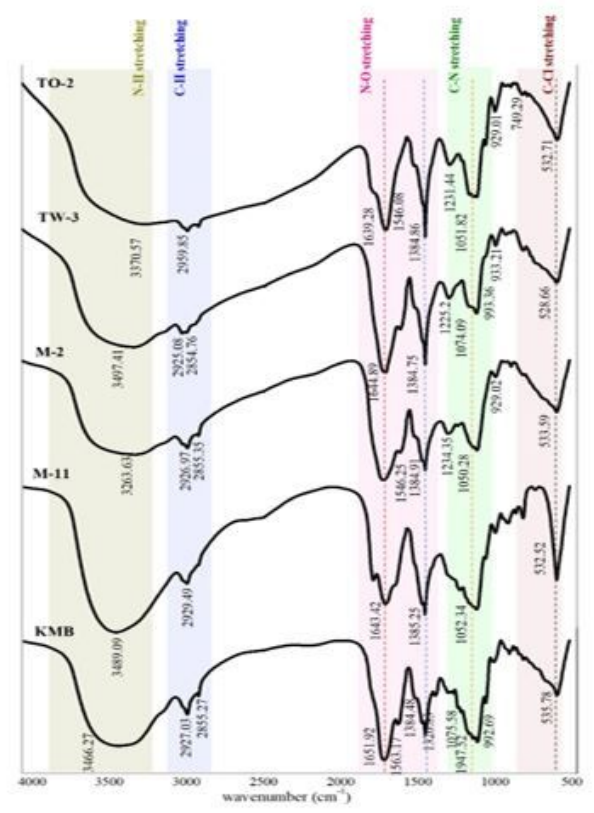

\section{Figure 2}

a) Thin Layer Chromatogram analysis of solvent extracted samples for pyrrolnitrin production. b) FTIR spectra of solvent extracted samples from bacterial isolates for the presence chlorine and nitro group. 

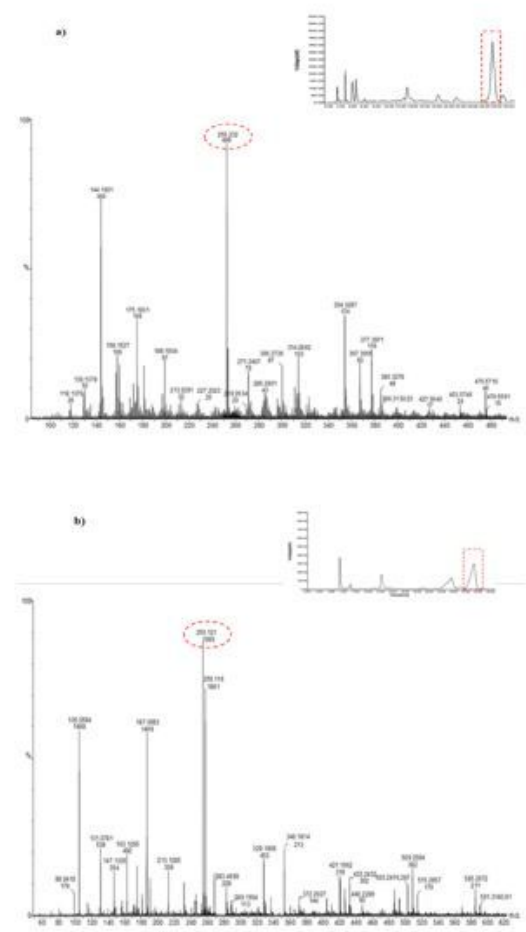

\section{Figure 3}

High pressure liquid chromatogram and UV detector 730D. LC-MS analysis of pyrrolnitrin secretion by Serratia marcescens TW-3 and Serratia nematodiphila TO-2. (a) The top panel shows extracted ion chromatograms at $\mathrm{m} / \mathrm{z}=256.232$ for the Serratia marcescens TW-3 and Serratia nematodiphila TO-2 (bottom chromatogram) represented ion chromatograms at $\mathrm{m} / \mathrm{z}=256.121$ of bacterial extract using $\mathrm{C} 18$ column ( $\mu \mathrm{m})$ with mobile phase of acetonitrile: water ( $20 \%$ ).

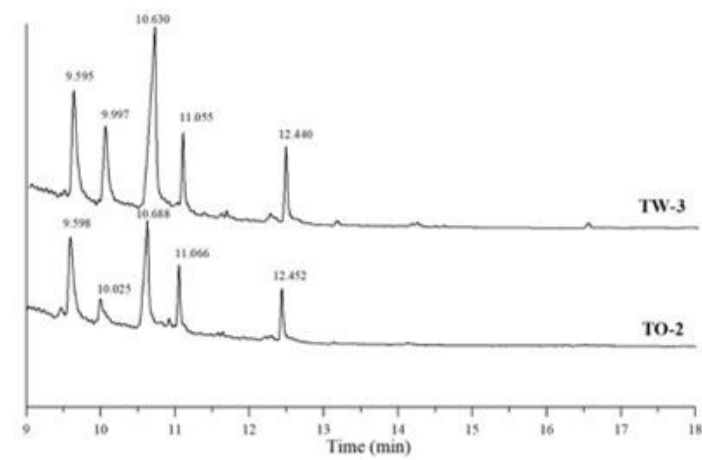

\section{Figure 4}

GC chromatogram of two selected bacterial solvent extracted samples (a) TW-3 and (b) TO-2. 
Fig. 5: a)

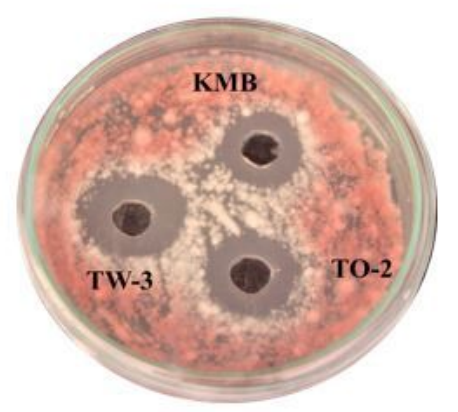

b)

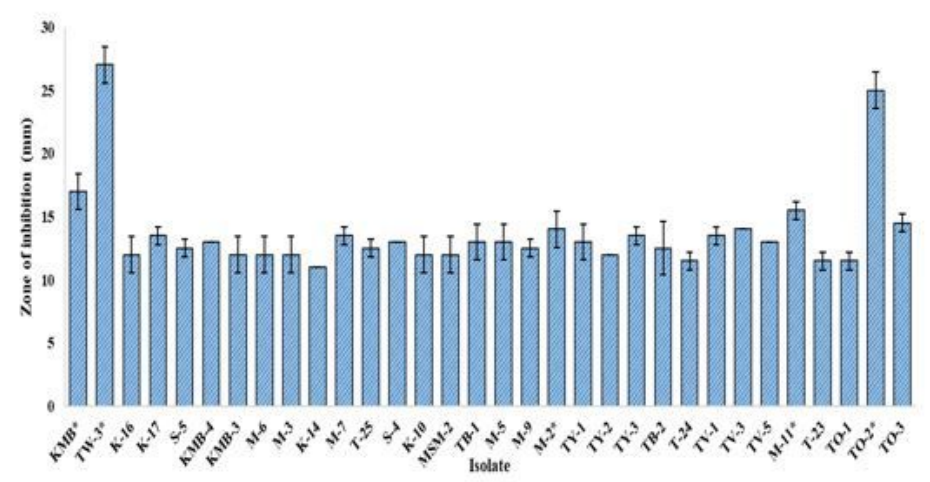

Figure 5

In vitro assay for antifungal activity of extracted sample from rhizobacterial isolates KMB, TW-3, M-2, M-11, TO-2 against F. oxysporum MTCC 9913. (a) Plate image of antifungal assay, (b) Bar graph diagram plotted zone of inhibition ( $\mathrm{mm}$ ) against isolates. Values of zone of inhibition (mm) represented with error bars as Mean \pm SD. 
Fig. 6: a)
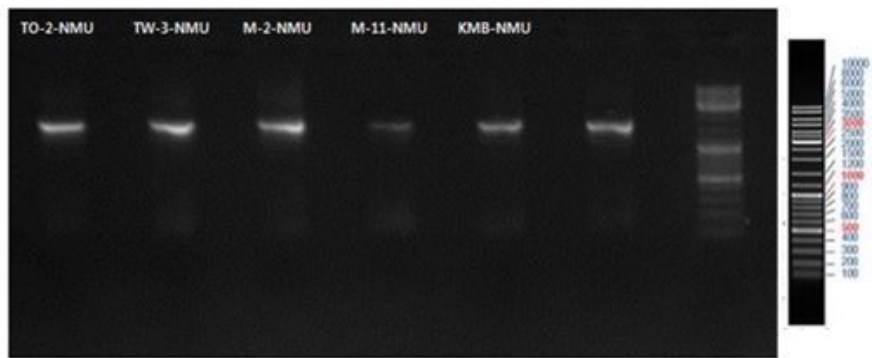

b)

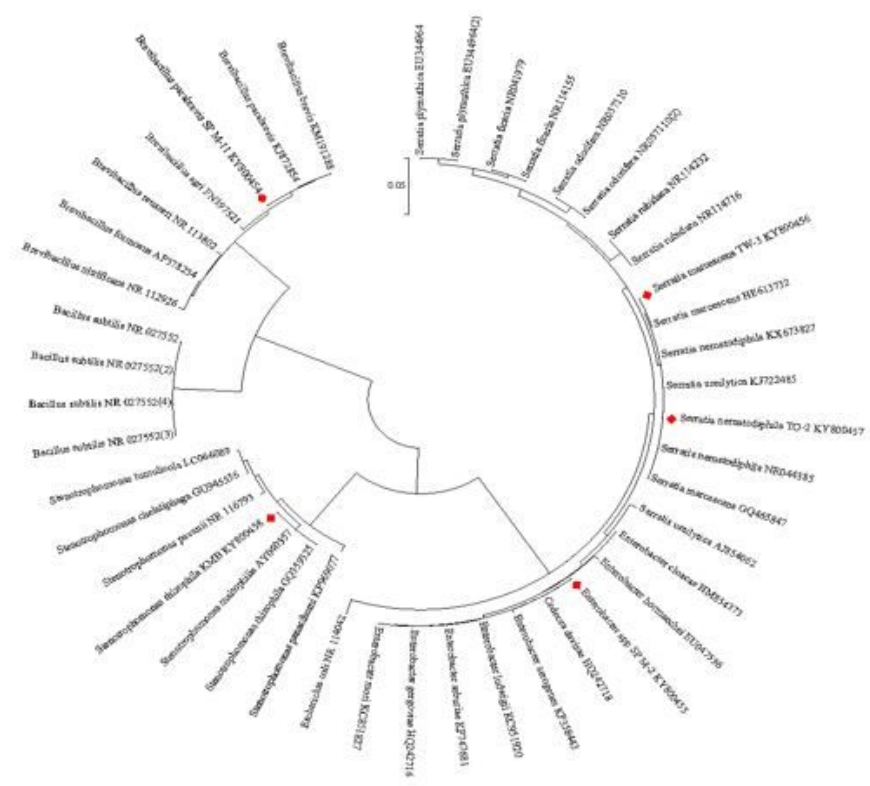

Figure 6

a) Agarose gel electrophoresis image of PCR-amplified product of bacterial 16S rRNA gene for identification of bacteria on $1 \%$ agarose gel with sharp band produced by bacterial strains: TO-2; TW-3; M-2; M-11; KMB and $1 \mathrm{~kb}$ marker on the right. b) Neighbor-joining phylogenetic trees of rhizobacterial isolates TO-2; TW-3; M-2; M-11; KMB namely, Serratia marcescens, Serratia nematodiphila, Enterobacter spp., Brevibacillus parabrevis and Stenotrophomonas rhizophila based on the 16S rRNA sequences. GenBank accession numbers are shown in parentheses of bacterial names. c) Electrophoresis gel image of PCR products amplified from genomic DNA of isolated bacterial strains for prn gene sequencing (a) TO-2: Serratia nematodiphila KY800457 (b) TW-3: Serratia marcescens KY800456 (c) M-2: Enterobacter spp. KY800455(d) M-11: Brevibacillus parabrevis KY800454 (e) KMB: Stenotrophomonas rhizophila KY800458. M: marker $(3 \mathrm{~kb})$ 


\section{Fig. 7 a)}

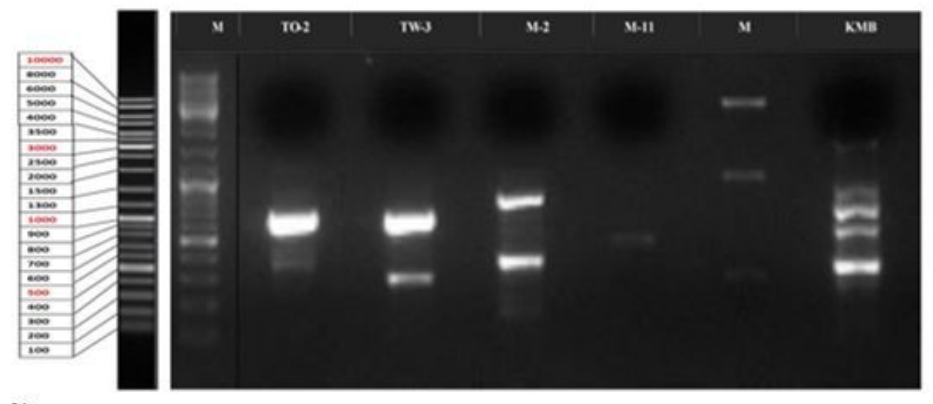

b)

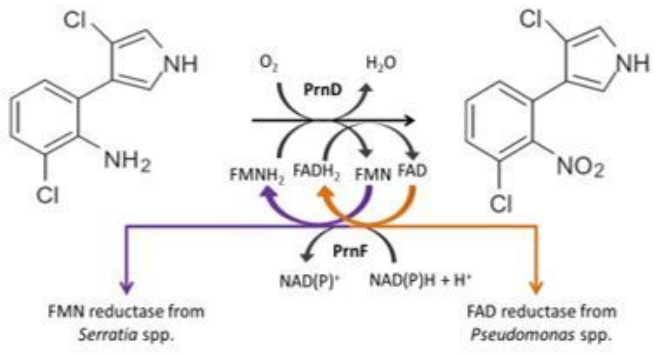

Figure 7

: a) Ribbon diagram from homology modelling of superimposed 3SLV (pink color) and PrnF (blue color) structures generated in the PyMol.2.3. b) Ramachandran plot of torsion angle created from PROCHECK server characterized for PrnF modelled retrieved from sequence of S. marcescens TW-3 (KY800456). Color shades represent different regions in the plot; red color region (where no steric clashes) permitted for a-helical and $\beta$ sheet whereas, yellow color for allowed region (atoms are allowed to come a little closer together) Most favoured regions : A, B, L Additional allowed regions : a, b, I, p Generously allowed regions : $\sim a, \sim b, \sim 1, \sim p$ Disallowed regions : Number of Glycine reside: Showed in triangles c) Docking of the FMN and NADPH with receptor binding pocket of PrnF modelled developed by homology modelling. FMN molecule with red colour while green colour indicated NADPH molecule where potential hydrogen bonds represented by yellow dashed lines and distance are in OA. The figures generated in PyMol 2.3. 
Fig.8: a)

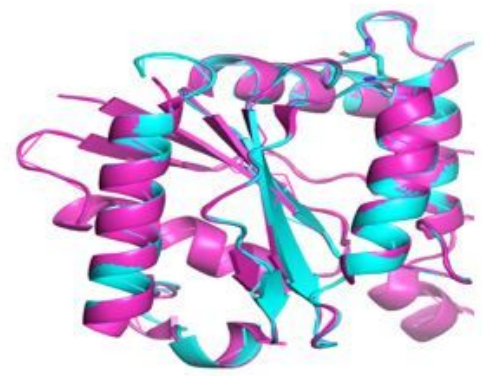

b)

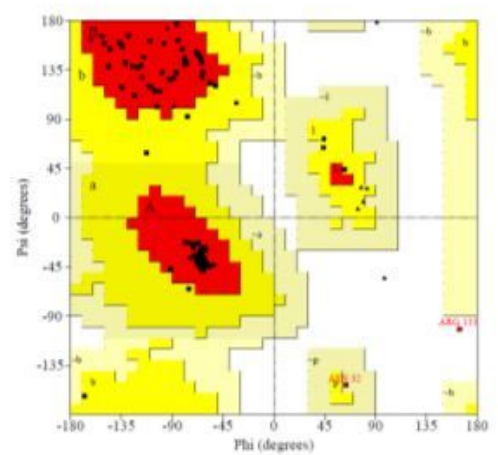

c)

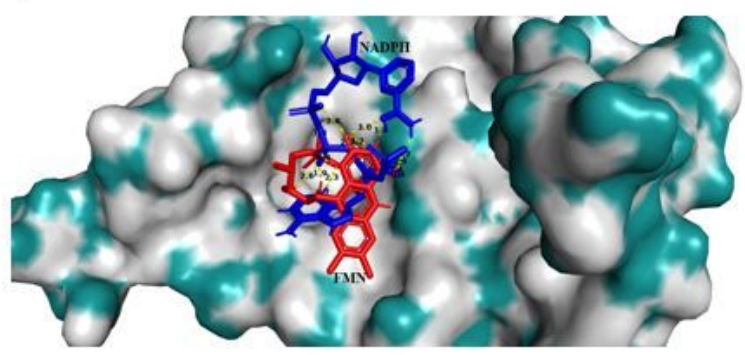

Figure 8

Figure 8

\section{Supplementary Files}

This is a list of supplementary files associated with this preprint. Click to download.

- Graphicalabsract.docx

- Supplementarymethod.docx 